\title{
An analysis of the prosperity of China's marine economy
}

\author{
Li Xuemei
}

Ocean University of China, Qingdao, China

Benshuo Yang

Ocean University of China - Laoshan Campus, Qingdao, China, and Yun Cao, Liyan Zhang, Han Liu, Pengcheng Wang and Xiaomei Qu

Ocean University of China, Qingdao, China

\begin{abstract}
Purpose - China's marine economy occupies an important position within the national economy, and its contribution thereto is constantly improving. The overall operation of the marine economy shows positive developmental trends with potential for further growth. The purpose of this research is to analyse the prosperity of China's marine economy, reveal trends therein and forecast the likely turning point in its operation.

Design/methodology/approach - Based on the periodicity and fluctuation of China's marine economy development, China's marine economic prosperity indicator system is established from five perspectives. On this basis, China's marine economic operation prosperity index can be synthesised and calculated, then a dynamic factor model is constructed. Using the filtering method to calculate China's marine economic operational Stock-Watson index, Markov switching has been used to determine the trend to transition. Furthermore, China's current marine economic prosperity is evaluated through analysis of influencing factors and correlation analysis.

Findings - The analysis shows that, from 2017 to 2019, the operation of the marine economy is relatively stable, and the prosperity index supports this finding; meanwhile it also exposes problems in China's marine economy, such as an unbalanced industrial structure, low marine economic benefits and insufficient capacity for sustainable development.

Originality/value - Through the analysis of the prosperity of China's marine economy, the authors reveal the trends in China's marine economy and forecast its likely future turning point.
\end{abstract}

Keywords Prosperity of marine economy, Stock-Watson index, Markov switching

Paper type Translated paper

\section{Review and analysis of the prosperity of China's marine economy}

At present, the marine economy occupies a key position within the national economy and constantly promotes the development thereof. The marine economy is generally undergoing healthy development, with strong momentum and potential to grow. Since 2003, the state has continuously issued policy documents to support the development of the marine industry. At the same time, various national development plans, as well as the 17th, 18th and 19th National Congresses of the $\mathrm{CPC}$, have all made important strategic plans for the development of the

(C) Li Xuemei, Benshuo Yang, Yun Cao, Liyan Zhang, Han Liu, Pengcheng Wang and Xiaomei Qu. Published in Marine Economics and Management. Published by Emerald Publishing Limited. This article is published under the Creative Commons Attribution (CC BY 4.0) licence. Anyone may reproduce, distribute, translate and create derivative works of this article (for both commercial and noncommercial purposes), subject to full attribution to the original publication and authors. The full terms of this licence may be seen at http://creativecommons.org/licences/by/4.0/legalcode

This research is supported by the National Social Science Fund Major Projects (14ZDB151); National Science Foundation of China under Grants (41701593, 71371098, 71571157); National Key Research and Development Program of China (2016YFC1402000); The Ministry of Education Philosophy and Social Sciences Development Report Cultivation Project (13JBGP005).

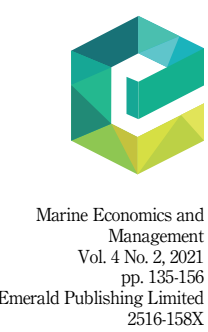


MAEM

4,2

marine economy. Therefore, the marine industry develops rapidly thanks to national policy support and the importance attached to the marine economy by the relevant national departments. From 2017 to 2019, in terms of marine career development, China was progressing, the policy effect was obvious, China's international marine status was enhanced, the structure of the marine economy was further optimised and adjusted, and its contribution to the improvement of livelihoods increased, the scope of "Marine silk road" trade was enlarged, the spatial distribution of marine development was optimised, and the prosperity index was rising.

\subsection{Review of the structure of the marine economy}

In recent years, China's marine development has been growing in scale, and new achievements have been made in the building of a powerful maritime country, ushering in a new era of maritime development.

The growth indicators of the marine economy are basically stable. Since 2017, China's main marine economic growth indicators, such as the Gross Ocean Product and the added value of major marine industries, have been operating within regulatory targets. The rate of growth of the gross output value of the major marine industries has reached $7.5 \%$ in 2019 , and the proportion of the GOP in the GDP of the coastal areas has reached more than $17 \%$ for three years. The contribution of the marine economy to the national economy has continuously increased. Currently, the world economic situation is severe, China's marine economy rate of growth is affected: the rate of growth decreased but remained indicative of a high level of development, thus the marine economy "engine" role continued to develop.

The economic structure of the marine economy continued to improve. From 2017 to 2019, the level of development of China's marine industry has continuously risen, and the economic structure has been continuously optimised. The proportion of marine primary and secondary sector of the economy has been decreasing, and the proportion accounted for by the tertiary sector has been rising continuously for three years, reaching $60 \%$ in 2019 . The role of "stabilisers" in the marine service industry has been further enhanced. At present, the overall level of development of China's marine industry is not high, and the level of development of emerging industries, hi-tech industries and strategic industries is relatively slow; marine industrial restructuring is still facing a more serious situation.

The size of the marine employment population has been continuously expanding. From 2017 to 2019, the rate of growth of the employment of personnel in major marine industries has been maintained at around $8 \%$, and the number of maritime-related workers has been increasing. The labour force is abundant, but there remains a shortage of high-level professionals, and the productivity of employment is not high. Therefore, in the process of cultivating innovative marine talents, we need to strengthen the training of professional talents in the field of marine hi-tech operations, accelerating the construction of strong professional qualities and innovative abilities among our marine talent pool.

\subsection{Review of the level of development of China's marine industry}

Since 2017, China's major marine industries have been developing steadily, and the marine economy has reached a new stage of progress every year. In 2019, China's Gross Ocean Product was $8,941.5 \mathrm{bn}$ yuan, an increase of $6.2 \%$ over the previous year. The GOP accounted for $9 \%$ of China's total GDP and $17.1 \%$ of the GDP of coastal areas. The marine industry realised an added value of 3,572.4bn yuan in the whole year, up by $7.5 \%$ year on year.

The structure of major marine industries is stable. From the perspective of marine industrial structure, there are currently 12 major marine industries in China, which have basically formed the three pillar industries of Binhai Tourism, Undersea Marine Transportation and Marine Fishery, with other major marine industries as the supporting structure, for the further development of emerging industries to provide some support. 
The rate of growth of major marine industries is steady. In terms of the rate of growth of marine industry, the rate of growths of Marine Shipping industry, Coastal Tourism, Marine Scientific Research, Education Management Service Industry and Marine Biological medicine industry are obvious in recent years. In 2019, the rates of growth of these industries were 11.3, 9.3, 8.3 and $8.0 \%$. China is in urgent need of a breakthrough in the development of emerging marine industries. The development of high-end, hi-tech and strategic emerging industries is an inevitable path. In the future, strategic emerging industries such as Marine New Energy Development and Seawater Utilisation offer significant potential.
Prosperity of China's marine economy

\subsection{Review of marine economic benefit}

Since 2017, the marine economy has gradually become a new growth point for China's economy. The cooperation in markets, technology and information, which is linked by the marine economy, has become increasingly close. The development of the marine economy has been changing to a quality-benefit model.

The production efficiency of traditional marine industries has improved significantly. From 2017 to 2019, the input-output ratio of traditional marine industries has been continuously declining, which means that in the development process of traditional marine industries, the consumption of intermediate means of production has been reduced along with the continuous improvement of its scientific and technological level, the rate of utilisation has been significantly increased, and the marine economic benefits have been significantly improved. At the same time, the operating efficiency of enterprises related to the marine economy has increased significantly, and their profitability has been continuously enhanced. According to statistics from the Oceanic Administration, in 2018, the cost profit margin of the marine economy, the profit margin of the main business income of those enterprises involved in the sea and the profit margin of the assets increased by $3.9,3$ and $2.1 \%$, respectively, marine productivity almost tripled in 2018 compared to that in 2011 .

The development efficiency of emerging marine industries has improved steadily. Marine emerging industries are located at the high end of the marine industrial chain, characterised by high scientific and technological content, eco-friendliness and an abundance of resources, playing a guiding role in the development of the marine economy and the improvement of benefits, including the Marine Bio-pharmaceutical industry, the Marine New Energy industry and the Marine Modern Service industry. According to data from the Ministry of Natural Resources, the country's iconic emerging marine industries grew rapidly in 2019, especially in industries with better infrastructure and breakthroughs in related scientific and technological development than previous years; however, China's marine emerging industries remain in the early stage of development, there are still many developments possible among late starters, given the relatively weak support and low rate of transformation of scientific research achievements.

\subsection{Review of the economic level of development of coastal areas}

The economic aggregate of coastal areas is huge; in 2019, for example, the total GDP of the 14 coastal provincial administrative units (excluding Hong Kong Macao and Taiwan) exceeded 52 trillion yuan, accounting for $52.7 \%$ of GDP. The promotion of the coastal areas to China's economic development is mainly reflected in two aspects: on the one hand, improving China's technological strength and narrowing the gap of advanced technological development between China and developed countries. On the other hand, coastal areas, as the first to have developed, can provide strong support for the western region and the coordinated development of the eastern, central and western regions.

The economic development of the coastal areas is regionalised: because of the difference in historical basis and natural endowment conditions, the economic growth of different regions in coastal provinces is different, and the southern region has developed faster. In 2019, the 
MAEM

4,2

average GDP rate of growth of the coastal provinces was the highest in the south, while the GDP rate of growth of the northern regions was slower due to the traditional industrial structure of the north and its being less closely linked to the fast-growing Internet economy than the south.

The economic development of coastal areas promotes the sustainable development of the marine economy. Since 2017, the economic development of the coastal areas has played an clear role in promoting the development of China's marine economy, but China's coastal regional economic development as a driving force for the development of the marine economy, its promotional effect on the marine economy has yet to be fully played out; the main reasons are that the marine industry is dominated by traditional industry, the development of intensive processing is lagging behind, the support capacity of science and technology is insufficient, and the shortage of talents in marine industry is a bottleneck. In the future, it is necessary to increase policy support and personnel support in the restructuring and upgrading of marine industries, increase cooperation among institutions of higher learning, enterprises and scientific research institutes and form an integrated technological innovation platform of "production, learning, research, and application", we will work to raise the level of industrial technological innovation.

\subsection{Review of the sustainable level of development of China's marine economy}

From 2017 to 2019, China's marine economy has developed steadily and continuously and achieved certain results.

Effective prevention and control of marine disasters: China is a large maritime country with a long coastline, which also means that the risk of marine disasters is higher, the negative effects of marine disasters on the lives of residents and the development of industries may cause great disruption in coastal areas, causing greater impacts on key industries such as Marine Fisheries, Coastal Transportation and Binhai Tourism, it even poses a serious threat to the safety of people's lives and property. From 2017 to 2019, the total investment in marine disaster prevention and control has been increasing every year, effectively reducing the economic losses caused by marine disasters.

Marine pollution control is beginning to show results. The Chinese Government attaches great importance to the prevention and control of marine environmental pollution by formulating policies to prevent, mitigate and control pollution and damage to the marine environment caused by human activities and climate change. Since 2017, China's industrial wastewater discharge rate has exceeded $98 \%$. With the promulgation of various regulations on the management of marine environment and the attention of relevant departments in various regions, the number of marine pollution control projects in coastal areas has been increasing to good effect. According to local characteristics and existing problems, departments and governments at all levels have selected and established marine nature reserves covering more than $5 \mathrm{~m}$ hectares by 2019.

Marine scientific research is advancing: from 2017 to 2019, marine science and technology have entered a period of leap-frog development. China's scientific research fund income has maintained a rapid growth, scientific research output has increased several times over, the marine science and technology personnel team has been continuously expanded, and marine scientific research capacity and conditions have been further optimised and improved. China still, however, has significant potential for development in marine equipment technology, to close the certain gap between China and the USA, Japan and other maritime powers.

\section{Compilation of China's marine economic prosperity index}

Considering the characteristics of China's marine economic development, herein we measure the marine prosperity from the five aspects reviewed in Section 1: the Synthetic Prosperity Index method, Dynamic Factor method, SW Prosperity Index Method and Markov Dynamic Transfer method are used to compile the Marine Economic Prosperity Index. 
2.1 China's marine economic indicators of prosperity

2.1.1 Principles and basis of China's marine economic prosperity indicators. In this paper, the indicators chosen to measure the prosperity degree of China's marine economy mainly highlight the unique characteristics of China's marine economic development, the basic principles underpinning the Marine Economic Prosperity Evaluation Index system are determined by considering the characteristics and trends of marine economic development, the perfection of resources and environment protection: it mainly includes the rationality, comprehensiveness, similarity, importance, sensitivity and stability.

China still needs to improve its statistics collated in relation to her marine economy, and many of the data cannot fully meet the needs of this analysis, so, when selecting the indicators of China's Marine Economic Prosperity Index, more consideration should be given to the perfection of the current design of marine economic statistics in China, as well as to the stage and degree of marine economic development. Combining the selection and standard of the indicators of the economic prosperity of the USA, the European Union, Japan and South Korea, we can see that the factors affecting the economic prosperity are complex. Although different countries and organisations differ in their selection of indicators, there are some common features in certain areas. The present work makes reference to the commonness of economic prosperity indicators formulated by various countries and international organisations and combines them with the reality of China's marine economic development, forming criteria for selecting three indices, which reflect the structural characteristics of the marine economy, rationally forecasting the development thereof and timeously reflecting the sensitivity of fluctuations therein.

\subsection{Selection and analysis of China's marine economic boom indicators}

According to the characteristics of the development of China's marine economy, and based on the opinions of many experts and published reports, we summarise five major indicators as the first-class indicators used to evaluate China's marine economic prosperity; they are main Marine Economic Structure Index, Marine Industry Level of development Index, Marine Economic Benefit Index, Coastal Area Economic Level of development and Coastal Economy Sustainable Development Index. Therefore, a Marine Economic Prosperity Index System consisting of 38 secondary indicators is formed.

The main Marine Economic Structure Index is a comprehensive index reflecting structural changes in the process of the development of China's marine economy, which can not only reflect the structural emphasis and rationality in the analysis of the past development of China's marine economy, it can also predict the future focus of China's marine economic development. This work mainly stems from the structure of China's marine industry, marine production structure and marine employment population structure to determine secondary indicators. Specifically including the main marine industry gross output growth, marine industry import and export growth, including 11 indicators therein.

The Level of Development Index of the Marine Industry is a comprehensive index reflecting the development situation of various marine industries in China. It can reflect the development status of various marine industries in China and the future development prospects of various industries and can predict that the further development of the marine economy in the future provides data support thereto. In this work, according to China's marine industry to determine the division of secondary indicators, we specifically include the marine fishery value-added rate of growth, the marine oil and gas industry value-added rate of growth, including six indicators therein.

The Marine Economic Benefit Index is a comprehensive index that reflects the labour consumption and the comparison of labour results in the marine development activities. It can reflect the return that can be produced by the per unit input of the marine economy allowing
Prosperity of China's marine economy 
MAEM

4,2

140

analysis of the profitability of the marine industry, it can also predict the new growth point of the marine economy in the future, which is beneficial to maintaining the stability of marine economic development in China. Herein we mainly select the secondary index from two aspects: the marine production efficiency and the output efficiency of new and old industries. Specifically including the emerging industry added value accounted for the traditional industry added value proportion, marine total labour productivity, including four indicators therein.

The Economic Level of Development Index of the coastal area reflects the comprehensive economic strength of the coastal area supporting the marine economy. The good economic development of the coastal area can promote the development of marine economy. The more economically developed coastal areas are more conducive to the industrial adjustment and transformation of the marine economy and provide impetus for the further development of the marine economy. Here, from the coastal area perspectives of prices, consumption, incomes, import and export levels, we select secondary indicators. Specifically including the coastal area price level, the coastal area per capita disposable income level, including seven indicators therein.

The Index of the Sustainable Level of Development of coastal economy is used to measure and analyse whether the economic development power is sufficient and whether it can develop better and faster in the future. The degree of exploitation and richness of marine resources will impose different requirements on the sustainable development of marine economy. The analysis of the sustainable development ability of marine economy is beneficial to the better, faster and healthier development of marine economy in the future. Specifically, we include the area of marine nature reserves and coastal areas of industrial wastewater discharge rate, involving nine indicators therein.

\subsection{Testing and criteria for China's marine economic boom indicators}

The marine economy is a complex operating system, which is affected by many factors, such as differences in its nature and essential characteristics. Furthermore, the state of the marine economic system is not static but has evolved gradually under the influences of the internal and external environment; therefore, the fluctuation of the relevant indicators to measure the development of the marine economy in various aspects also tends to exhibit unstable development: the dynamic changes therein are relatively complex, and the correlation among them is also very different; therefore, it is necessary to test the stability of each index and select a relatively stable index, which will be incorporated into the construction of Marine Economic Prosperity Index System.

Since most of the original statistical indicators of the marine economic system have a certain time trend, that is, they show temporal development, for example: the National Gross Domestic Product, the coastal area Gross Domestic Product as well as each type of main industry added value, cause its prosperity to be difficult to judge. Therefore, to avoid the potential influence of any temporal trend on the index system of prosperity, we test the stability of all the alternative indices corresponding to this kind of index and analyse the results: the final selection of the prosperity index is based on the smoothness of the index.

\subsection{Data selection and data pre-processing for business indicators}

To make the indicators selected in this paper more representative, the research selected the relevant data of China's marine areas from 2002 to 2019. Annual data are used for analysis based on availability of indicator data and other factors. The data are mainly taken from the China Marine Statistical Yearbook, China Marine Economic Statistical Bulletin, China Marine Disaster Bulletin, China Statistical Yearbook and so on. The methods of standardisation, singularities and in-filling of omitted data are used to pre-process the original data. 
(1) Standardisation: because of the different characteristics of different data, there are dimensional differences among them, which leads to the problem whereby different data cannot be directly compared in the process of analysis. To solve this problem, data can be standardised. Data standardisation mainly includes the use of mean values, initial values and so on. In the present work, the initial value method is selected for standardisation.

(2) Singularity processing: a singularity is an outlier and usually leads to significant bias in research conclusions, so it is necessary to correct these indicators.

Robust regression and diagnostic methods are the main methods to detect singular points. By observing and analysing the residual error, the robust regression method can detect singular values. The diagnostic method mainly uses the Markov distance or leverage value between data samples to detect the singularity in the data set. The method of dealing with the singular point mainly uses the difference prediction method and the substitution method.

(3) Missing data: during data collection, due to temporarily inaccessible information and other reasons, there will inevitably be omissions, which will lead to deviations in model output. To complete the data set, we use certain methods to fill in for data omissions.

The present work relied on use of the moving average method, the exponential smoothing method and the random forest technique. The principle of the moving average method is to calculate the multi-period average value according to the original time series, thus forming a new average value time series. Based on the moving average method and according to its drawbacks, the exponential smoothing method is optimised to retain relevant historical data and give different (exponentially varying) weights to the historical data at different distances from the interpolated data. When many datapoints are missing, it is more effective to construct a random forest with multiple decision trees to in-fill the missing values.

\subsection{Calculation of the marine economic prosperity index}

2.5.1 Composite index calculation. The Composite Index, also known as the Prosperity Composite Index, is a composite index which is obtained from the weighted sum of the changes of the characteristic indices as weights. The index cannot only reflect the fluctuation of the comprehensive indices in an economic cycle, but also predict the future (in economic terms). The specific algorithm is as follows:

First, the symmetric rate of change of a single index is calculated:

$$
C_{i t}=\frac{d_{i t}-d_{i t-1}}{\left(d_{i t}+d_{i t-1}\right) / 2} \times 100=\frac{200\left(d_{i t}-d_{i t-1}\right)}{d_{i t}+d_{i t-1}}
$$

The rate of change for symmetry is standardised to $A_{i}$ :

$$
A_{i}=\sum_{t=2}^{N}\left|C_{i t}\right| /(N-1)
$$

The normalised values of the symmetric rate of change are $S_{i t}$ :

$$
S_{i t}=C_{i t} / A_{i}
$$


MAEM

4,2

\section{2}

The symmetry rate of change after multi-indicator standardisation is as follows:

$$
R_{t}=\left(\sum_{i=1}^{k} S_{i t} \cdot W_{i}\right) /\left(\sum_{i=1}^{k} W_{i}\right)
$$

The standardised factor $F$ is given by:

$$
F=\frac{\left(\sum_{t=2}^{N}\left|R_{t}\right|\right) /(N-1)}{\left(\sum_{t=2}^{N}\left|P_{t}\right|\right) /(N-1)}
$$

The standardised formula for the Synchronised Index is:

$$
V_{t}=R_{t} / F
$$

With the original index having Order $I_{1}=100$ :

$$
I_{t}=I_{t-1} \times \frac{200+V_{t}}{200-V_{t}} \quad t=2,3, \ldots, m
$$

The Composite Index is given by:

$$
C I_{t}=\frac{I_{t}}{\bar{I}_{0}} \times 100 \%
$$

2.5.2 Dynamic factor model and SW prosperity index. Dynamic Factor Model (DFM) is widely used in the calculation of the Prosperity Index. Stock and Watson (1993) constructed the Stock-Watson (SW) Prosperity Index based on which they considered the SW Prosperity Index to be a single, non-observable factor that could have a different effect on the Economic Prosperity Index. The general form of the DFM of the state space is:

$$
\begin{gathered}
\Delta \mathrm{y}_{i t}=\gamma_{i}(L) \Delta c_{t}+\mu_{i t}, \quad i=1,2, \ldots, k \\
\varphi(L) \Delta c_{t}=\varepsilon_{t} \\
\psi_{i}(L) \mu_{i t}=v_{i t}
\end{gathered}
$$

Among them is the SW Prosperity Index, which reflects the state of the prosperity; because the model contains non-observable variables, the traditional estimation method cannot be solved, so the form transformed into state space is solved by Kalman filtering.

\subsection{Markov state transition model}

The Markov Switching Model (MS) can effectively calculate the turning point in a business cycle and overcome the problem of asymmetry when analysing the economic cycle and financial time series. In the present work, we employ the MS method to determine the turning point of China's marine economic cycle. The transfer forms are as follows:

$$
\begin{aligned}
& \left(\mathrm{y}_{t}-\mu_{s_{t}}\right)=\phi_{s_{t-1}, 1}\left(\mathrm{y}_{t-1}-\mu_{s_{t-1}}\right)+\phi_{s_{t-2}, 2}\left(\mathrm{y}_{t-2}-\mu_{s_{t-2}}\right)+\cdots \\
& +\phi_{s_{t-r},}\left(\mathrm{y}_{t-r}-\mu_{s_{t-2}}\right)+\varepsilon_{t}, \varepsilon_{t} \sim N\left(0, \sigma_{s_{t}}^{2}\right)
\end{aligned}
$$

As the state variable, suppose the economic development can be in one of two states prosperity or recession - when the economy is prospering, the value is 1 , when the economy is 
in recession state, the value is 2 . Due to the unobservable discrete variables in the model, in the estimation process, it is necessary to use a Hamilton filter to infer the probability and use the maximum likelihood to calculate the probability density of the mixed normal distribution of the dependent variables at each time point.

\subsection{China's marine economic prosperity index compilation}

2.7.1 Classification of indicator types and calculation of composite indices. Firstly, the data pertaining to 38 indices are pre-processed, then the existing indices are divided into periods by the methods of grey correlation, time difference correlation analysis and fuzzy and clustering analysis. Finally, 38 indicators are divided into 15 leading indicators, 7 synchronous indicators and 16 lagging indicators. Then we use the K- L information method, Kendall consistency test method and Granger causality analysis method to determine the first order (or lag order) of each index.

The composite indices for the years 2003-2019 are calculated using the composite index calculation method for each category (Table 1).

According to the data in Table 1, the composite index of China's marine economic performance is plotted (Figure 1).

\begin{tabular}{|c|c|c|c|c|c|c|c|c|c|c|c|c|}
\hline Year & 2003 & 2004 & 2005 & 2006 & 2007 & \multicolumn{2}{|c|}{2008} & \multicolumn{2}{|c|}{2009} & \multicolumn{2}{|c|}{2010} & 2011 \\
\hline Leading index & 95.78 & 96.44 & 97.31 & 98.09 & 99.16 & \multicolumn{2}{|c|}{98.9} & \multicolumn{2}{|c|}{100.55} & \multicolumn{2}{|c|}{100.76} & 101.26 \\
\hline Synchronised index & 96.8 & 98.22 & 99.07 & 99.69 & 99.99 & \multicolumn{2}{|c|}{100.57} & \multicolumn{2}{|c|}{99.4} & \multicolumn{2}{|c|}{100.93} & 101.01 \\
\hline Lagging index & 98.39 & 98.99 & 98.57 & 97.15 & 98.34 & \multicolumn{2}{|c|}{99.26} & \multicolumn{2}{|c|}{99.54} & \multicolumn{2}{|c|}{98.99} & 99.84 \\
\hline Year & 2012 & 2013 & 2014 & 2015 & & & 20 & & & & & \\
\hline Leading index & 101.78 & 102.11 & 102.21 & 102.36 & & .97 & & & & & & \\
\hline Synchronised index & 100.77 & 100.42 & 100.73 & 100.21 & & .13 & & & & & & \\
\hline Lagging index & 99.93 & 100.88 & 100.39 & 101.13 & & .58 & & & & & & \\
\hline
\end{tabular}

Prosperity of China's marine economy
$-$ 
MAEM

4,2

\section{4}

In Figure 1, the three composite indices showed an upward trend, with the composite index of leading indicators being the steepest, reaching its peak in 2015, and then decreasing slightly, gradually tending to be stable; after 2008, the Composite Index of lagging indicators showed a slight upward trend, while the composite index of lagging indicators showed an upward trend after 2006. The data in Table 1 are used to plot changes in China's Marine Economic Performance Composite Index over time (Figure 2).

From 2003 to 2013, the Composite Index of China's marine economic performance showed overall growth, rising from the sub-cooling area of the stagnant space to the moderate area of the prosperous space, and the increase in the index was small in 2006 After 2013, the rate of growth of the prosperity composite index decreased and remained in the moderate region of the prosperity space. In 2016, the prosperity composite index decreased significantly. After 2017, the Prosperity Composite Index returned to the desired path.

2.7.2 Solution of dynamic factor model and calculation of $S W$ prosperity index. According to the different indices of China's marine economic operation, five synchronous indices are selected to calculate the DFM and the SW Index: the rate of growth of the national gross product, the rate of growth of the gross output value of the major marine industries, the proportion of the employment of the major marine industries in the employment in coastal areas, the rate of growth of the added value of the marine transportation industry and the proportion of the added value of the major marine industries in the Fixed Assets Investment of the coastal areas. Five first-order difference stationary sequences are obtained by firstorder difference and ADF test.

The model parameters $(R, P, Q)$ are $(2,2,2)$, as determined through repeated tests of the lag orders of each variable, and the value in 2003 is equal to 100 by calculating and adjusting the mean value through Kalman filtering. Finally, the DFM of China's marine economic operation is established, and the relevant parameters are as follows:

Figure 2.

Composite index curve of China's marine economy

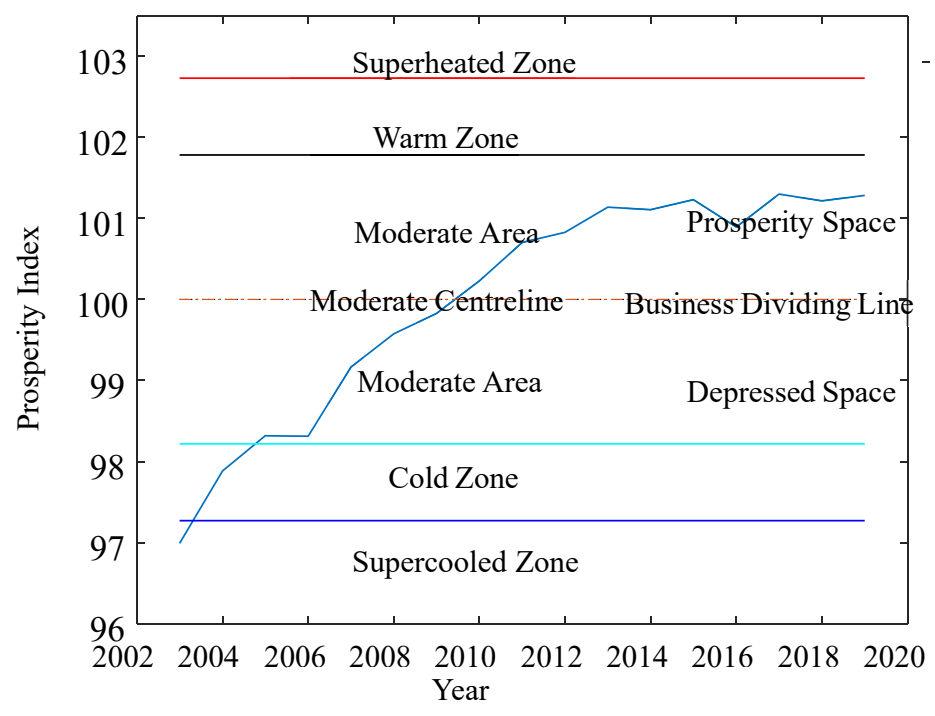


Measurement equation:

$$
\begin{aligned}
& Y_{1 t}=1.5675 C_{t-1}-1.5223 C_{t-2}+\mu_{1 t} ; \quad Y_{2 t}=5.2333 C_{t-1}-5.1908 C_{t-2}+\mu_{2 t} \\
& \text { (8.9314) (-8.8312) } \\
& Y_{3 t}=-0.2678 C_{t-1}+0.3293 C_{t-2}+\mu_{3 t} ; \quad Y_{4 t}=-2.427 C_{t-1}+2.4947 C_{t-2}+\mu_{4 t} \\
& (-2.1436) \quad(2.1762) \\
& Y_{5 t}=-3.6270 C_{t-1}+3.7027 C_{t-2}+\mu_{5 t} \\
& (-2.3459) \quad(2.3719) \\
& \text { (8.2148) (-8.1573) } \\
& (-2.4956) \quad(2.5336)
\end{aligned}
$$

Prosperity of China's marine economy

Equation of state:

$$
\begin{aligned}
& C_{t}=1.529 C_{t-1}-0.529 C_{t-2}+\eta_{t} \\
& (59.2937) \quad(-25.4998) \\
& \mu_{1 t}=0.3090 \mu_{1 t-1}+0.0263 \mu_{1 t-2}+\varepsilon_{1 t} ; \quad \mu_{2 t}=0.6674 \mu_{2 t-1}-0.2676 \mu_{2 t-2}+\varepsilon_{2 t} \\
& \text { (2.378) } \quad(-1.886) \\
& \text { (2.884) (-1.869) } \\
& \mu_{3 t}=0.9576 \mu_{3 t-1}-0.2079 \mu_{3 t-2}+\varepsilon_{3 t} ; \quad \mu_{4 t}=0.3781 \mu_{4 t-1}-0.0548 \mu_{4 t-2}+\varepsilon_{4 t} \\
& \text { (4.187) (-1.945) } \\
& \mu_{5 t}=0.4483 \mu_{5 t-1}+0.2671 \mu_{5 t-2}+\varepsilon_{5 t} \\
& \text { (2.565) (-2.194) } \\
& \text { (2.178) (1.784) }
\end{aligned}
$$

The Kalman filter calculates the unobservable variable and the China Ocean Economic Performance SW Prosperity Index (Table 2).

According to Table 2, the maximum value of China Ocean Prosperity Operating SW Prosperity Index reached 113.69 in 2010, and the minimum value was 100 in 2003. The changes in ocean prosperity (as evinced by the SW Prosperity Index) are shown in Figure 3.

Figure 3 indicates that the trend of the SW-SCPI curve of China's marine economic operation is roughly the same as that of the Synchronous Index Curve, and the range of fluctuations of the SW-SCPI curve of China's marine economic operation is bigger: from 2003 to 2008, the index showed an increasing trend, from the sub-cooled areas in the stagnant space to the moderate areas in the prosperous space, and the development of the marine economy was in a state of rapid expansion. After 2008, the SW-prosperity Index of China's marine economic operation fluctuated: the index fell in 2009 and in 2011 fell to a moderate level in the recessionary space, owing to the ongoing effects of the economic crisis since 2008 and the European debt crisis; after 2013, the index fluctuated more frequently but less widely, the index basically remains within the moderate area of the prosperity space, presenting one kind of rising trend after dynamic adjustment.

2.7.3 Simulation of Markov state transition model and identification of the turning point in business cycle fluctuation. Based on the Markov state transition model and the obtained SW Prosperity Index of China's Marine Economic Operation, a MATLAB ${ }^{\mathrm{TM}}$ program is developed to simulate the state of China's marine economic operation. The simulation parameters are listed in Table 3.

\begin{tabular}{lccccccccc}
\hline Year & 2003 & 2004 & 2005 & 2006 & 2007 & 2008 & 2009 & 2010 & 2011 \\
\hline SW sentiment index & 100 & 101.65 & 106.13 & 110.69 & 111.75 & 112.05 & 110.5 & 113.69 & 103.99 \\
\hline Year & 2012 & 2013 & 2014 & 2015 & 2016 & 2017 & 2018 & 2019 \\
\hline SW sentiment index & 113.67 & 110.78 & 109.01 & 112.44 & 108.55 & 107.7 & 109.65 & 109.98
\end{tabular}

Table 2. China ocean economic performance SW prosperity index 
MAEM

4,2

\section{6}

Figure 3.

China ocean economic performance SW prosperity index

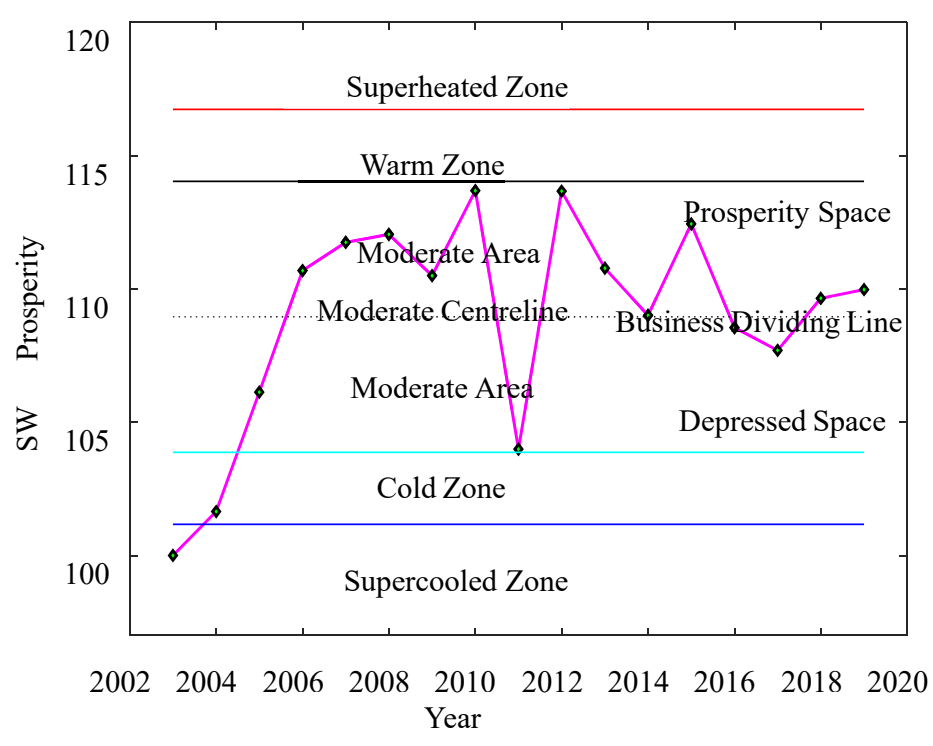

Parameters in state 1 (coefficient value (standard error, $p$-value))

Residual standard deviation: $0.2392(0.0420,0.00)$

Mean constant: $8.3502(2.5698,0.01)$

Degrees of freedom: 296.8957 (585.5966, 0.62)

AR parameters

Lag 1: $0.9223(0.0257,0.00)$

Parameters in state 2 (coefficient value (standard error, $p$-value))

Residual standard deviation: $3.2681(0.7797,0.00)$

Mean constant: $95.2510(0.0002,0.00)$

Degrees of freedom: $340.9487(0.0008,0.00)$

AR parameters

Lag 1: $0.0377(0.0090,0.00)$

Transition probabilities matrix (standard errors in parentheses)

Table 3.

Calculation of parameters of the Markovian state transition model for China's marine economy
$0.80(0.24) 0.59(0.33)$

$0.20(0.12) 0.41(0.29)$

Expected duration of regimes

Expected duration of Regime \#1: 4.99 time periods Expected duration of Regime \#2: 1.69 time periods

As can be seen from Table 3, the two states simulated by the Markov state transition model are better, the standard deviation of the corresponding residuals, the continuity of the mean and the estimated parameters of the AR model all pass the test; and the transition matrix is obtained, when the economy is in state 1 , the probability of maintaining State 1 is 0.80 , and the 
probability of transitioning to State 2 is 0.20 . When the economy is in State 2 , the probability of transitioning to State 2 is 0.59 , the probability of remaining in the doldrums is 0.41 . The transition diagram of the Markov state is shown in Figure 4.

Observation of Figure 4 shows that the Markov state-transition diagram of China's marine economic operation basically corresponds to the SWI curve of China's marine economic operation, the difference between them is that the Markov state-transition model can filter some small points of mutation. From 2003 to 2010, China's marine economy remained in State 1 , indicating that the marine economy is in a state of growth. Since 2011, the Marine Economy has started to exhibit several fluctuations: the state of the Marine Economy in 2011 indicates a recession, followed by a rapid rise in 2012, a renewed recession in 2014 and a gradual return to State 1 after 2018; China's Marine Economic Development is currently growing.

\section{The developing situation in China's marine economy}

\subsection{Analysis of the factors influencing the prosperity index of China's marine economy}

To explore the factors influencing China's Ocean Economic Prosperity Index, the China Ocean Economic Prosperity Index is selected as the dependent variable, because the SW index is calculated from the Synchronous Index, to ensure the correctness and reliability of the model, repeated experiments and calculations involving four influencing factors from the leading indicators are used to explore the effects of the SW Prosperity Index on China's marine economy as a dependent variable.

The factors selected here are the rate of growth of added value of marine shipbuilding industry, the proportion of new marine industries, the rate of growth of added value of marine scientific research, education and the Management Service Industry and the rate of growth of total investment in Marine Disaster Prevention and control. The sample time was 2003-2019, and the regression results are as follows:

$$
Y_{t}=\underset{(2.941)}{0.182 X_{1, t-1}}+0.5093 X_{2, t-1}+0.227 X_{3, t-2}+0.167 X_{4, t-1}+97.045
$$

The goodness of fit of the regression equation is 0.723 , the $F$-value is 6.5273 , the equation is deemed statistically significant, all variables pass the $t$-test and are thus significant. According to the regression parameters, the lag time of the antecedent variable has a positive effect on the SW-SCPI of China's Marine Economy, it will add 0.182 units to the next index, because development of the marine shipbuilding industry will not immediately lead to huge economic growth, but will need to put those outputs to use to generate greater returns. The increase of the proportion of new marine industries will bring about a positive increase in the value of the marine economy in the next period, because the new marine industries can accrue higher profits than traditional marine industries, giving new impetus to the long-term
Prosperity of China's marine economy

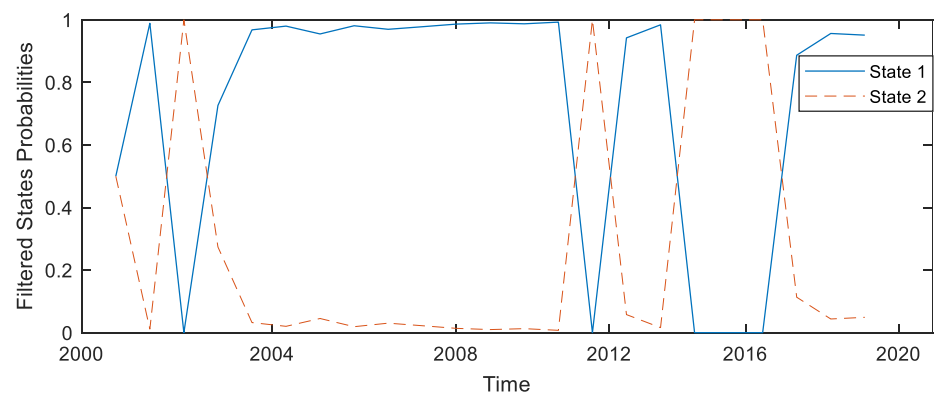

Figure 4.

Markov statetransition diagram for

China's marine economy 
MAEM

4,2

148

development of the marine economy. The changes in the value-added rate of growth of the Marine Scientific Research and Education Management Service Industry will bring greater impetus to the development of China's marine economy in the medium and long terms, and the investment in Marine Scientific Research and education will guarantee the breakthrough of China's Marine hi-tech development, compared to other indicators, it takes longer for the increase in Marine Scientific Research, education and management services to translate into marine economic benefits. The increase in the total investment in marine disaster prevention and control can better guarantee the safety of life and property of people living along the coast and is an important guarantee of the maintenance of normal economic life.

\subsection{Correlation analysis: the China Ocean Economic Prosperity Index}

Here, by using the Composite Index of China's marine economic operation and prosperity as the SI and the CI of China's Macro Economic Prosperity Index, the author constructs a vector autoregression model and develops a correlation analysis of China's Marine Economic Prosperity Index over the sample interval from 2003 to 2019. The SI data have been modelled in the previous section, and the CI data are taken from the National Bureau of Statistics of the People's Republic of China.

Firstly, the stability of SI and CI sequences is assessed. The unit root test is conducted by way of the ADF test. The results show that both SI and CI sequences are stationary (see Table 4).

The variance decomposition method can better explain whether there is correlation between the variables and its strength, and at the same time, the impulse response function is applied to analyse the dynamic characteristics of the model.

3.2.1 A VAR model test of the relationship between marine economic boom and macroeconomic boom in China. By constructing a VAR model, we analyse the relationship between China's marine economic prosperity index and macro-economic prosperity. According to the AIC information rule, the optimal lag time of the model is determined. The lag time is determined as three periods, and then the stability of the established VAR model is ascertained.

The VAR model is used to analyse the dynamic characteristics of the whole system over time when the error term is in effect, and the key assumption is that only the fluctuation term of the variable is thus affected; volatility terms of the remaining endogenous variables do not change (see Figure 5).

\subsubsection{The boom correlation analysis of China's marine economy and macro-economy.}

(1) China's marine economy and China's macroeconomic boom are related: Figure 6 shows that there is a strong correlation between the marine economic boom and a macro-economic boom. The effect of the macroeconomic system of operation on the marine system is mainly concentrated in the early stage, and that in the later stage is relatively low: the effect endured and through the impulse response function, the boom correlation response characteristics between the two can be described both intuitively and accurately.

It can be seen from Figure 6 that, when the impact on China's macroeconomic prosperity index is created, the SI index continues to rise in response, from the second period to the third period,

Table 4.

ADF test results

\begin{tabular}{lccl}
\hline Variable & ADF test value & p-value & Is the sequence stationary? \\
\hline SI & -3.543 & 0.0069 & Yes \\
CI & -3.531 & 0.0361 & Yes \\
\hline
\end{tabular}


Inverse Roots of AR Characteristic Polynomial

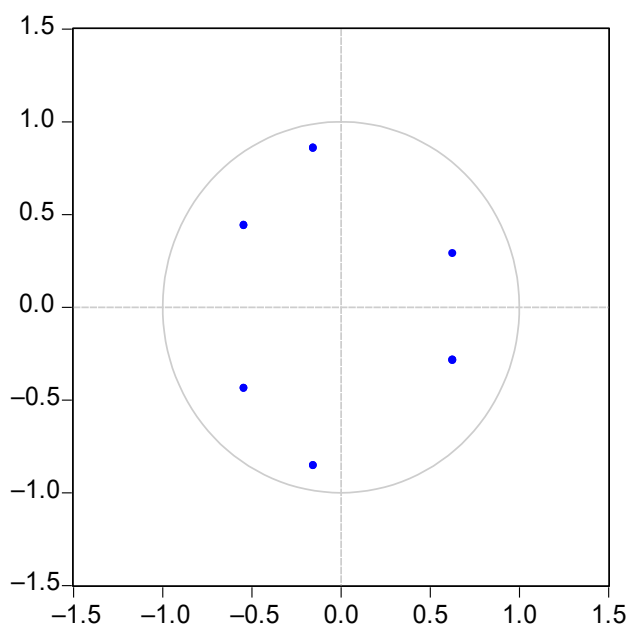

Prosperity of China's marine economy

Figure 5. Stability testing of the VAR model related to China's marine economic boom

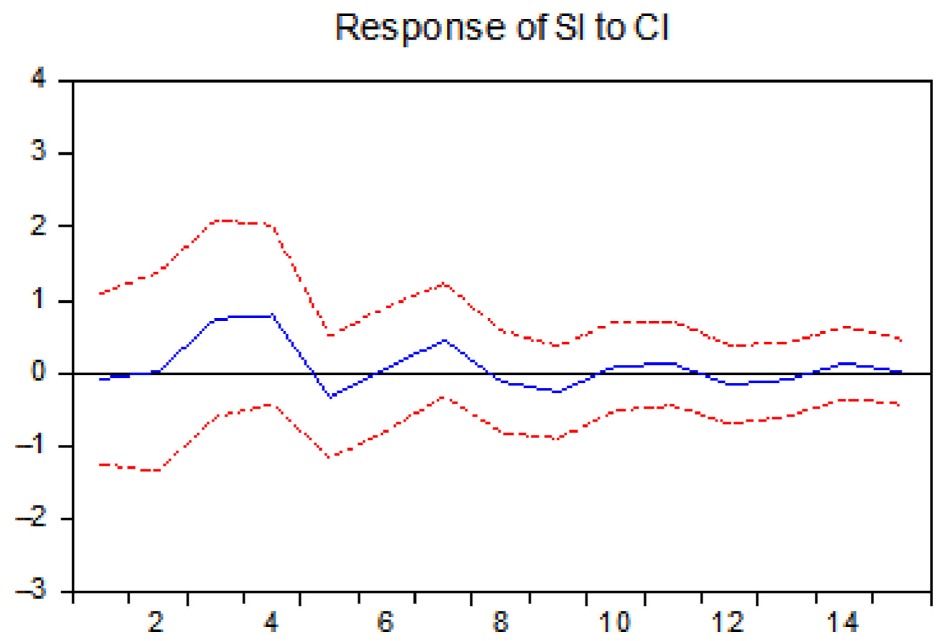

Figure 6.

The response of

China's marine economic boom to China's macroeconomic boom

continuing to maintain its upward momentum, and then rises slightly to the fourth period, reaching its highest point. Thereafter, the upward trend reverses, and it begins to fall linearly to its lowest point in the fifth period. The initial volatility is very intense, and then the degree of volatility slowly decreases. From this, it can be concluded that China's macro-economic prosperity and China's marine economy are highly correlated, with a long response time, and the impact is concentrated in the short term, while in the long term, the impact is very weak.

(2) The autonomous response of China's marine economy: Figure 7 shows that, in the initial period, the volatility is high. The internal impulse of China's marine economy declined rapidly, reaching its lowest point in the second period, bottoming out, constantly fluctuating, alternating between positive and negative, and the impact 
MAEM

4,2

\section{0}

Figure 7.

Response to China's marine economy's autonomous shock

\section{Res ponse of SI to SI}

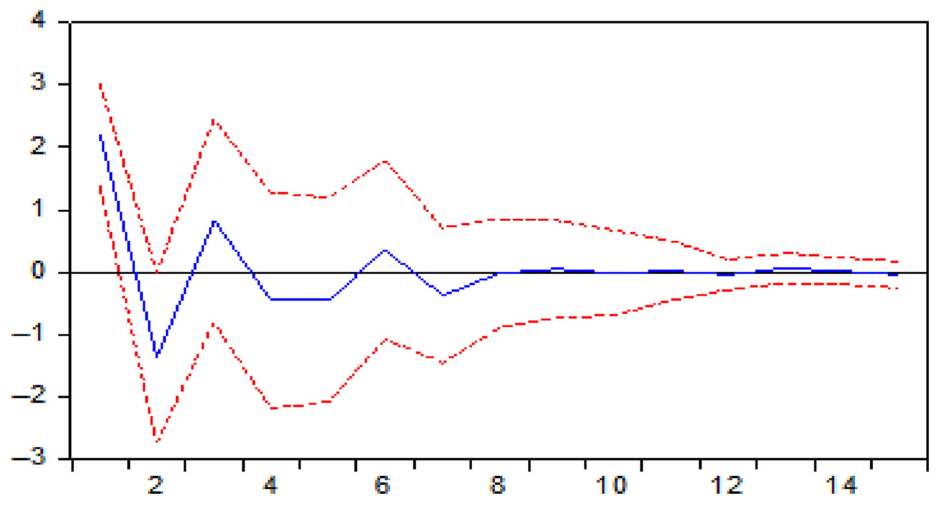

began in the sixth period. It gradually weakened and finally tended to disappear from the eighth period onwards. Figure 7 also demonstrates that the response of China's marine economic autonomous shocks is obvious, and the response time lag is relatively long, which shows to a certain extent that the internal mechanism of influence for China's marine economic system is strengthening, and its own sustainable development capabilities have been improved.

(3) Analysis of variance decomposition of China's marine economy

As shown in Table 5 and Figure 7, the fluctuations in China's marine economy are the main reason for the fluctuation of the marine economy. Although the macro-economy has a certain degree of influence, its proportional contribution is relatively low.

Figure 8 shows that the impact of China's macro-economic climate fluctuations on China's marine economy is relatively small, mainly arising from the impact of the marine internal system. From the beginning, the impact of China's macro-economic fluctuations has continued to increase. The first four periods see a large increase, and then although it has continued to rise, the amplitude is very low, it finally being maintained at about $16 \%$, that is, about $83 \%$ of the marine economic fluctuations can be explained by themselves, the remaining $17 \%$ can be explained by changes in China's macro-economy. It can be seen from this that although the macro-economic boom is closely related to the marine economy, the marine economy is relatively unaffected by macro-economic conditions, and the operation of China's marine economic system is relatively safe and stable.

\section{Prediction of China's marine economic development}

To better predict the prosperity of China's marine economy in the future, we use index direct, and indirect, forecasting methods to predict the future development trend of the country's marine economy based on some characteristics of marine economic data.

Table 5.

Variance

decomposition of China's marine economy

\begin{tabular}{lcccccrrrrr}
\hline Period & 1 & 2 & 3 & \multicolumn{1}{c}{4} & \multicolumn{1}{c}{5} & \multicolumn{1}{c}{6} & \multicolumn{1}{c}{7} & \multicolumn{1}{c}{8} & \multicolumn{1}{c}{9} & 10 \\
\hline S.E. & 6.907 & 8.357 & 8.733 & 8.746 & 9.155 & 9.219 & 9.426 & 9.473 & 9.511 & 9.589 \\
CI & 0.137 & 0.106 & 7.06 & 13.533 & 14.27 & 14.116 & 15.759 & 15.883 & 16.487 & 16.564 \\
SI & 99.63 & 99.89 & 92.94 & 86.467 & 85.73 & 85.884 & 84.241 & 84.117 & 83.513 & 83.436
\end{tabular}




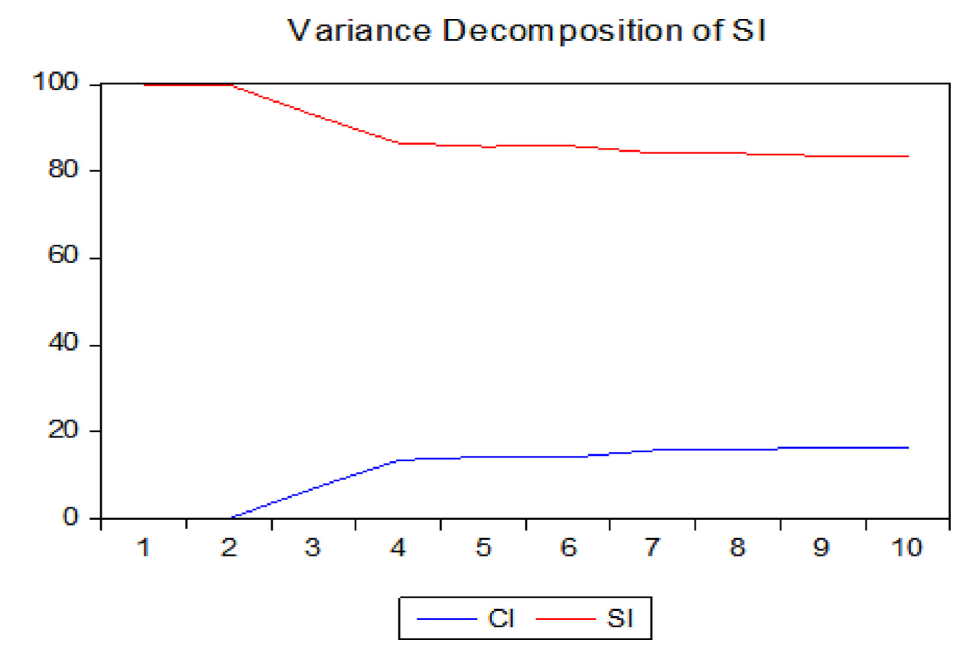

Prosperity of China's marine economy

151

Figure 8.

Variance decomposition diagram of China's marine economy

\subsection{Direct forecasting method to predict the prosperity of China's marine economy}

The marine economic index direct forecasting method is based on the original index model and results, using a grey forecasting method, neural network method, machine learning method, a moving average and exponential smoothing method to directly predict the index. This kind of forecasting method is intuitive, offering practicality in the cases involving missing data. Based on China's marine economic prosperity index, we forecast the next three years of the comprehensive composite index of China's marine economic operation prosperity and her marine economic operation SW prosperity index (Figures 9 and 10).

Figure 9 shows that the comprehensive synthetic index of China's marine economic operation prosperity obtained through direct prediction methods will continue to rise in the next three years, but the increase is small, and it remains within the moderate area of the prosperity space. In the hot zone, the country's marine economy has been adjusted from a rapid rise to a deep integration stage, the marine economic structure is becoming more rational, the marine tertiary industry is more comprehensive, the traditional marine industry is gradually improved, and the technological level of the emerging marine industry will

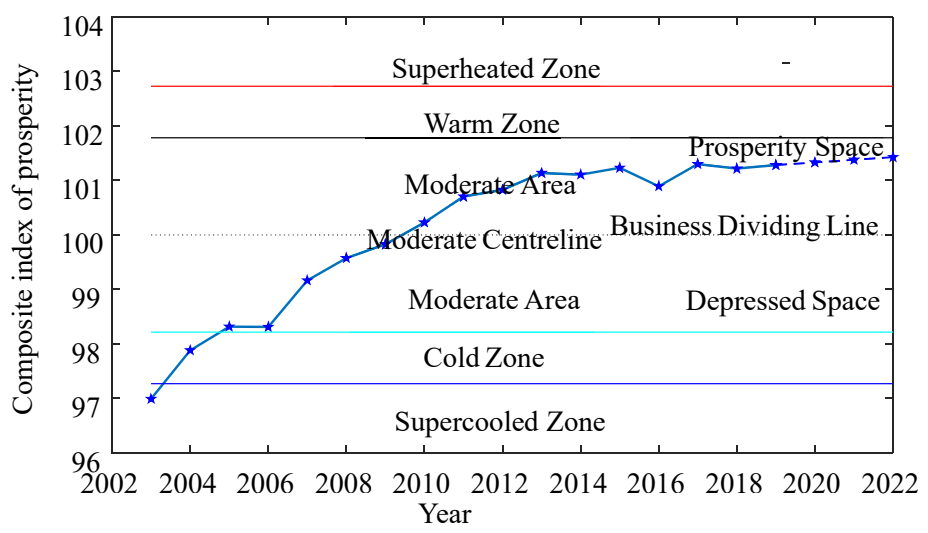

Figure 9.

Direct forecast results of the comprehensive synthetic index of China's marine economic operations from 2020 to 2022 


\section{MAEM}

4,2

\section{2}

Figure 10.

2020-2022 direct

forecast results of

China's marine

economic operation

SW prosperity index

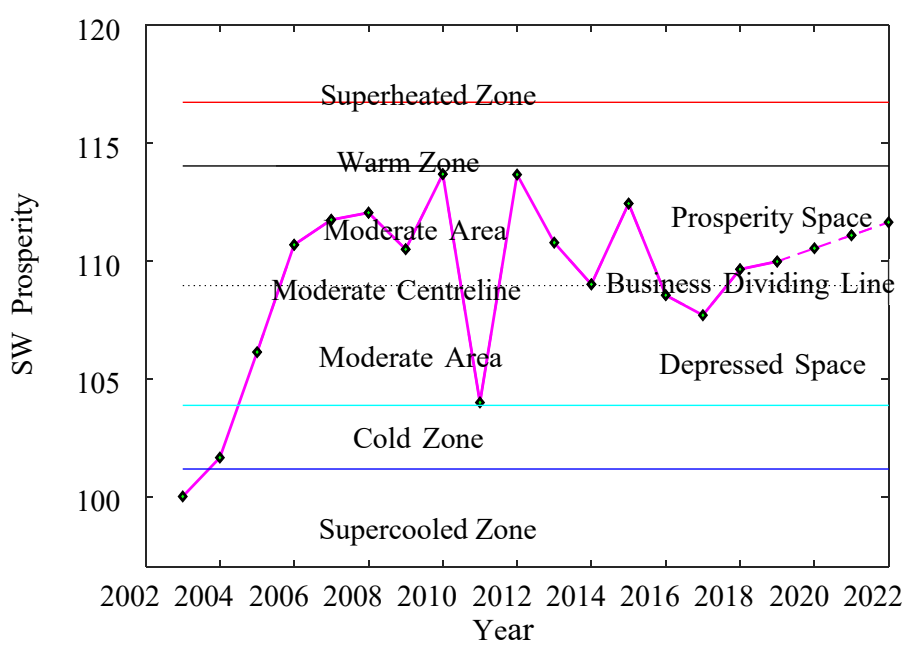

continue to increase. As for the composite index of the country's marine economic operations under the direct forecast, although there is an increase therein, its upward momentum is low. This is mainly due to the mutual influence of many factors such as the global economic downturn in recent years and slower overall domestic economic growth.

Figure 10 shows that the SW prosperity index of China's marine economic operation obtained by the direct prediction method will continue to increase in the next three years. The increase rate is not large but is relatively stable. Through the direct prediction, it can be inferred that the country's marine economic growth indicators will develop in a relatively stable manner in the next three years and will not fluctuate to any significant extent; the total amount of traditional marine industry indicators continues to grow, subject to the influence of the international economic environment, and the rate of growth of traditional marine industries may be affected; under the key support of the state, emerging marine industries, strategic industries and hi-tech industries may have breakthroughs and achieve rapid growth.

In the actual prediction process, although the direct prediction method can produce results simply and quickly, the direct prediction of univariate often suffers a loss of accuracy, especially given the insufficient calculation accuracy of the impact of some unexpected events, which has a negative impact on the accuracy of the prediction. Given the new corona virus pandemic and the continuous escalation of Sino-international trade friction, to improve the prediction accuracy of China's marine economic development, we also use indirect forecasting methods of prediction.

\subsection{The indirect forecasting method predicts the prosperity of China's marine economy}

The indirect forecasting method of marine economic indices is to predict the indicators used to calculate the index through use of a grey forecasting method, simultaneous equation model, neural network method, trend extrapolation method, exponential smoothing and combination optimisation forecasting. Here we combine collated data and the relevant quarterly data released in 2020 to predict the 38 indicators involved in the index calculation and use the index calculation method to predict indirectly the comprehensive composite index of China's marine economic operation prosperity and China's marine economic operation SW prosperity index for the period 2020-2022 (Figures 11 and 12). 
Figure 11 shows that the comprehensive synthetic index of China's marine economic operation prosperity obtained through the indirect forecasting method may see a short-term decline in 2020. The index will gradually return to normal in 2021 and 2022, and the index will maintain an upward trend. The synthetic prosperity index will be within 3 years, remaining within the moderate zone of the boom space; because of the corona virus pandemic in early 2020 , the production capacity of marine traditional industries has weakened compared with previous years. With the gradual and continuous control of the epidemic (in China), production capacity has gradually returned to normal, but its rapid spread elsewhere (at time of writing it remains out of control in many nations) and the continuous escalation of Sinointernational trade friction, the marine industry's imports and exports have been significantly affected, while related industries such as marine transportation and coastal tourism have also been greatly affected. From 2021 to 2022, it is expected that the pandemic will be better managed globally, the affected marine industries will gradually return to normal, and marine economic development will recover.

It can be seen from Figure 12 that the SW prosperity index of China's marine economic operation obtained through the indirect forecasting method has shown a significant decline in
Prosperity of China's marine economy

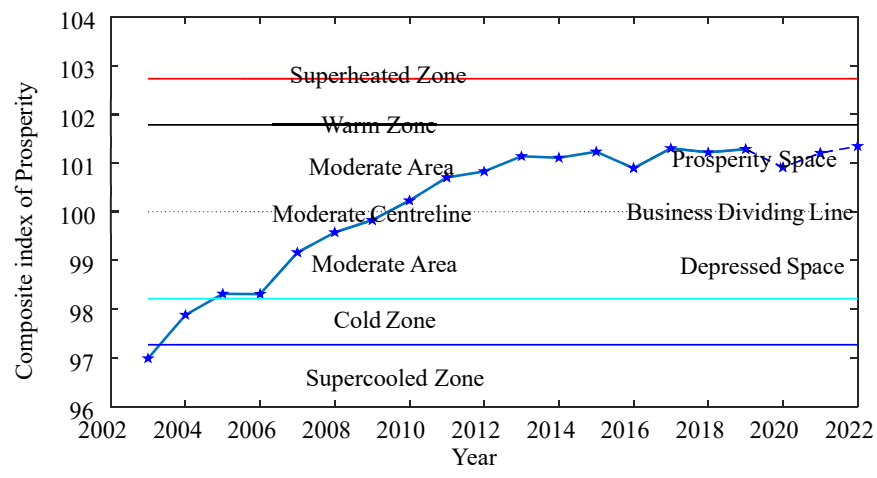

Figure 11

The indirect forecast results of the comprehensive synthetic index of

China's marine economic operations from 2020 to 2022

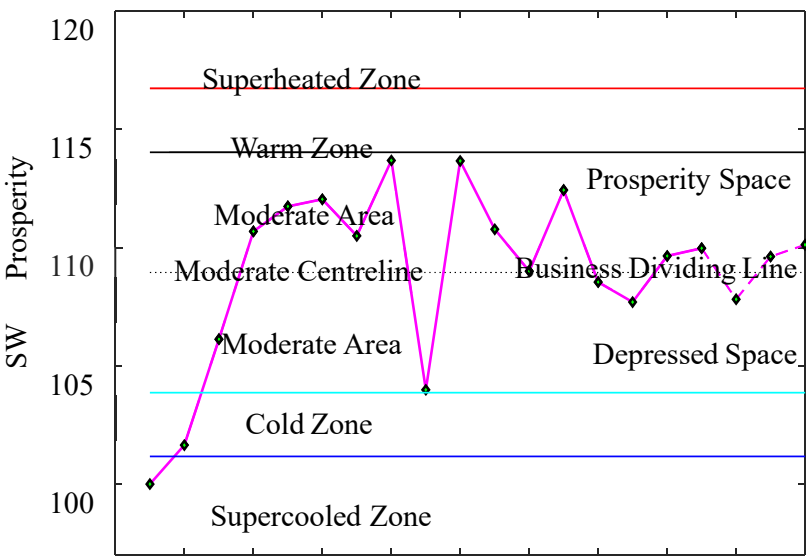

20022004200620082010201220142016201820202022 Year

Figure 12. 2020-2022 China's marine economic operation SW prosperity index indirect forecast results 
MAEM

4,2

154

2020, falling from the moderate area of the prosperous space to the moderate area of the depressed space, mainly affected by the corona virus pandemic. For example, emerging models such as webcasting and on-line delivery under the influence of network technology and location advantages have become a new trend in the current era. The marine economy has revealed a new exit strategy and, at the same time, China has also continued to make little progress in the development of marine science and technology, the prevention of marine disasters and the protection of marine resources, providing new impetus for the sustainable development of the country's marine economy. It is estimated that, from 2021 to 2022, the country's marine economy can resume its previous rate of development, and the prosperity index will return to a more favourable state.

\subsection{Proposals for China's marine economic prosperity policy}

At present, the country's marine economy has achieved leap-frog development, the maritime power strategy has been smoothly implemented, the Maritime Silk Road has become more prosperous, and the strategic position of the marine economic system has become increasingly prominent, thus attracting global attention, therefore, to promote the development of China's marine economy, the suggestions outlined below are made.

4.3.1 Develop the marine economy according to local conditions and promote the optimisation and upgrading of the marine industrial structure. Coastal areas should choose a marine economic development model that highlights regional characteristics and build a reasonable marine industrial structure. The optimisation and upgrading of the industrial structure require the enhancement of the role and status of the marine tertiary industry in the three major marine industries. On the one hand, government should issue corresponding strategic plans to guide the development of the marine culture and education industry and improve the "soft power projection" of the development of the marine economy; combining the industrial characteristics and geographical advantages of the coastal areas, accelerate the development of high-end service industries such as marine hi-tech industries and coastal tourism.

The healthy and stable development of marine strategic emerging industries can further enhance the prosperity of the marine economy. To promote the development of emerging industries, it is necessary to improve further the theoretical framework system of marine strategic emerging industries, implement the triple-combination of "stabilisation, expansion, and adjustment" and clarify key points. The focus on the main points allows targeted, precise efforts to be made to promote the optimisation of the industrial organisation structure based on the emerging marine industries and create a trend of benign cooperation between large and small enterprises with all attendant advantages.

4.3.2 Promote the establishment of innovative achievements in the marine industry and improve the core competitiveness of the marine industry. Marine science and technology innovation will continue to promote the development of the marine economy and play a key role in the development of new growth points in the marine economy; therefore, the improvement of core technology is particularly important for gaining an advantage in the global marine technology competition. To improve the level of core science and technology, we must first implement the basic capabilities of the marine industry and improve input and output efficiencies under the premise of ensuring safety, with sea-related enterprises and entrepreneurs as the main bodies, market mechanism adjustments as the basis and government adjustments as supplements thereto, improving the rationality and efficiency of resource allocation. Adhering to the combination of problem-oriented and demand-driven, adhering to the promotion of openness and autonomy, improving the integrity of the industrial chain and control over the global value chain and realising sustainable, healthy 
development of domestic industries requires independent control of the industrial value chain.

China should aim to promote the development of her marine industries and optimise the internal chain of the marine industry, so that the structure of emerging industries can better integrate with new-found vigour. China should aim to promote the construction of a policy system for emerging marine industries, continuously developing breakthroughs in key technological areas, and improve the core competitiveness of marine emerging industries. The focus should be on scientific research breakthroughs, first solving bottleneck problems, paving the way for the development of emerging industries and continuing to support core technological innovation. Under the dual impact of Sino-international trade friction and the global corona virus pandemic, we are striving to find new breakthroughs. Leading companies drive the full recovery of production capacity in the upstream and downstream ends of the industrial value chain, thus encouraging the high-quality development of the marine economy.

4.3.3 Improve marine environmental protection and ensure the sustainable and healthy development of the marine economy. The degree of marine environmental protection is essential to the sustainable development of the marine economy. We must pay attention to, and improve the protection of, scarce marine resources and continuously improve their utilisation efficiency, exploring the "ecological red line + ecological compensation" model of governance and market diversification therein, thus innovatively developing a green model for the marine economy, and a sound long-term mechanism for the protection and efficient use of scarce resources. In addition, it is necessary to improve and perfect the marine environmental protection legal system, promulgate relevant laws and regulations and increase penalties for destroying the marine environment, thus realising the protection, use and management of the sea in accordance with the law.

At the same time, it is necessary to use hi-tech methods to strengthen the monitoring of real-time marine data (such as $5 \mathrm{G}$ technology, drone technology, etc.), to ensure that the observational data can be accurately and timeously fed back to relevant departments and to understand what is happening in the process of marine environmental protection. The existing problems and drawbacks provide data support for marine environmental protection and use smart decision-making to promote the healthy development of China's marine environment. At the same time, through multiple channels, using multiple methods, on-line and off-line platforms are simultaneously promoted for implementation of marine environmental protection publicity and education work schemes.

\section{Reference}

Stock, J.H. and Watson, M.-W. (1993), "A simple estimator of cointegrating vectors in higher order integrated systems", Econometrica: Journal of the Econometric Society, pp. 783-820.

\section{Further reading}

Liang, N., Hu, Q., Wang, L. and Sun, J. (2020), "A study on the efficiency of resource allocation of Bohai Economic Rim”, Journal of the Yunnan Normal University, Vol. 52 No. 02, pp. 123-132.

Lin, H.H. (2020), "Face to 2030: global marine economy development influence factor, trend and countermeasure suggestion", Journal of the Pacific, Vol. 28 No. 01, pp. 50-63.

Ning, L. and Song, Z. (2020), "The dynamic relationship among Marine Science and Technology Innovation, Marine Total Factor Productivity and marine economic development: an empirical analysis based on panel Vector autoregression”, Research in Science and Technology Management, Vol. 40 No. 06, pp. 164-170. 
MAEM

4,2
Wang, B. and Han, L. (2017), “The impact of China's marine industrial structure on Marine Economic Growth: a panel threshold effect regression analysis based on 11 coastal provinces", Resource Science, Vol. 39 No. 06, pp. 1182-1193.

Wang, J. and Liu, X. (2016), "Identification of turning point of business cycle fluctuation in China based on Economic Prosperity Index”, Quantitative Economics Research, Vol. 000 No. 001, pp. 1-14.

Wang, Y. and Zhai, R. (2020), “Adjustment of marine industrial structure, spatial spillovers and coastal economic growth: an analysis based on the spatial panel data of coastal provinces in China”, Journal of Nantong University (Social Sciences Edition), Vol. 36 No. 01, pp. 97-104.

Wang, Z., Han, L. and Sun, C. (2017a), "The relationship between Marine Resources Development and marine economic growth in China”, Economic Geography, Vol. 37 No. 11, pp. 117-126.

Wang, Z., Lu, X., Sun, C., Han, Z. and Dong, X. (2017b), “The evolution of the center of gravity of China's marine economy and its influencing factors", Economic Geography, Vol. 37 No. 05, pp. 12-19.

Yin, K. (2016), A Study on the Monitoring and Early Warning of China's Marine Economic Cycle Fluctuation, 1st ed., People's Publishing House Beijing, p. 510.

Zou, W., Sun, C. and Tan, X. (2017), "Based on Bootstrap-DEA model, the spatial evolution of marine economic efficiency and the analysis of influencing factors in Bohai Economic Rim”, Geoscience, Vol. 37 No. 06, pp. 859-867.

\section{Corresponding author}

Li Xuemei can be contacted at: lixuemei@ouc.edu.cn

For instructions on how to order reprints of this article, please visit our website: 